\title{
Individual and institutional capacity-building for evidence-informed health policy-making in Iran: a mix of local and global evidence
}

Leila Doshmangir ${ }^{1,2}$, Hakimeh Mostafavi ${ }^{3}$, Masoud Behzadifar ${ }^{4}$, Bahareh Yazdizadeh ${ }^{5}$, Haniye Sadat Sajadi ${ }^{6}$, Edris Hasanpoor ${ }^{7}$, Mahdi Mahdavi $^{8}$ and Reza Majdzadeh ${ }^{5,9^{*}}$ (])

\begin{abstract}
Background: Providing valid evidence to policy-makers is a key factor in the development of evidence-informed policy-making (EIPM). This study aims to review interventions used to promote researchers' and knowledge-producing organizations' knowledge and skills in the production and translation of evidence to policy-making and explore the interventions at the individual and institutional level in the Iranian health system to strengthen EIPM.
\end{abstract}

Methods: The study was conducted in two main phases: a systematic review and a qualitative study. First, to conduct the systematic review, the PubMed and Scopus databases were searched. Quality appraisal was done using the Joanna Briggs Institute checklists. Second, semi-structured interviews and document review were used to collect local data. Purposive sampling was used and continued until data saturation. A qualitative content analysis approach was used for data analysis.

Results: From a total of 11,514 retrieved articles, 18 papers were eligible for the analysis. Based on the global evidence, face-to-face training workshops for researchers was the most widely used intervention for strengthening researchers' capacity regarding EIPM. Target audiences in almost all of the training programmes were researchers. Setting up joint training sessions that helped empower researchers in understanding the needs of health policy-makers had a considerable effect on strengthening EIPM. Based on the local collected evidence, the main interventions for individual and institutional capacity-building were educational and training programmes or courses related to the health system, policy-making and policy analysis, and research cycle management. To implement the individual and institutional interventions, health system planners and authorities and the community were found to have a key role as facilitating factors.

Conclusion: The use of evidence-based interventions for strengthening research centres, such as training health researchers on knowledge translation and tackling institutional barriers that can prevent well-trained researchers from translating their knowledge, as well as the use of mechanisms and networks for effective interactions among policymakers at the macro and meso (organizational) level and the research centre, will be constructive for individual and institutional capacity-building. The health system needs to strengthen its strategic capacity to facilitate an educational and training culture in order to motivate researchers in producing appropriate evidence for policy-makers.

Keywords: Evidence, Health policy, Health system research, Policy interventions

\footnotetext{
*Correspondence: rezamajd@tums.ac.ir

${ }^{9}$ Community Based Participatory Research Center, Tehran University of Medical Sciences, Tehran, Iran

Full list of author information is available at the end of the article
}

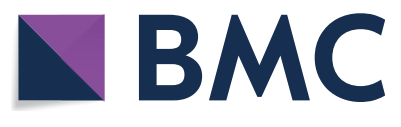

Ther Access This article is licensed under a Creative Commons Attribution 4.0 International License, which permits use, sharing, adaptation, distribution and reproduction in any medium or format, as long as you give appropriate credit to the original author(s) and the source, provide a link to the Creative Commons licence, and indicate if changes were made. The images or other third party material in this article are included in the article's Creative Commons licence, unless indicated otherwise in a credit line to the material. If material is not included in the article's Creative Commons licence and your intended use is not permitted by statutory regulation or exceeds the permitted use, you will need to obtain permission directly from the copyright holder. To view a copy of this licence, visit http://creativecommons.org/licenses/by/4.0/. The Creative Commons Public Domain Dedication waiver (http://creativeco mmons.org/publicdomain/zero/1.0/) applies to the data made available in this article, unless otherwise stated in a credit line to the data. 


\section{Background}

All governments resort to mechanisms such as public policy to solve the problems facing society, improve conditions and exploit opportunities. Various approaches have been proposed by different groups and organizations for enhancing public policy [1,2]. One such approach that has gained momentum in the last 10 years is evidence-informed policy-making (EIPM) [3]. EIPM is an approach for policy-making that takes into account the political context, availability of resources, and people and customer experiences in order to provide the right evidence at the right time in the right language for policy-making $[4,5]$. This approach enables policy-makers to make informed decisions using the best available evidence, which will ultimately improve health system performance [6].

EIPM can play a crucial role in designing, implementing and delivering better public policies and maintaining quality public services in the context of various situations.

A number of reports have provided credible information confirming that evidence produced through research can improve the health policy process by gathering valuable data regarding different phases of policy-making [7-9]. In other words, the promotion of EIPM can reduce the barriers to evidence utilization by health policy-makers $[10,11]$. It has been argued that policy-makers are simply the end-users of the evidence that is produced by researchers, so it is unrealistic to expect them to incorporate and adapt all policies to local conditions $[12,13]$. It is universally recognized that effective health systems that are evidence-based in their implementation are vital to improving health outcomes $[14,15]$.

In addition to the demand for evidence among policymakers, the supply of appropriate evidence to policymakers strengthens producer capacity and is a key factor in the expansion of EIPM. The increased use of evidence in policy-making means stronger capacity for evidence production on both the demand and supply side [16].

Advocates of EIPM argue that the depth and quality of knowledge used by policy-makers influence the effectiveness of policies. Necessary steps must be taken to use appropriate methods, interventions and strategies to produce the knowledge needed by policy-makers and to strengthen this policy-making approach [17]. In addition to other important factors such as the failure to correctly identify the problem or issue, and the lack of a problemsolving function that results in limited evidence-based policy-making, a lack of research-based solutions is also a critical issue. Studies and research evidence can help health policy-makers and managers evaluate current systems and design new policies and services based on their knowledge of failures and successes [18]. In addition, the use of evidence enables policy-makers to implement policies based on the best available evidence [19]. Some critics believe that there is a gap between policy-making requirements at the national level, the needs of society that must be met, and policy priorities and what motivates researchers to do research [14, 20]. On the other hand, researchers sometimes provide policy-makers with massive amounts of evidence that confounds and complicates the decision-making process.

Moreover, many countries are facing a number of barriers in terms of institutional shortcomings and gaps in knowledge and skills and capacity. In recent years, in line with the increasing global attention to the importance of evidence use in health polices, Iran's health system has been motivated to produce interventions and initiatives towards researcher capacity-building with the aim of promoting EIPM [21].

Although in recent years various measures and interventions have been implemented in Iran's health system to strengthen and institutionalize EIPM, in reality, obtaining and using high-quality evidence is a challenging issue, and many policy decisions are still not informed by evidence [22]. Also, the use of research evidence in health policies is not systematic, comprehensive and well institutionalized [10]. In some cases, health policies are rushed and politicized without sufficient research and evidence and without scientifically getting to the root of the problem [23]. For example, based on the evidence, the development and implementation of the Health Transformation Plan, one of the largest reforms of the health system, was not based on robust evidence, and now there are many challenges in its continuity [24, 25]. In 2015, when the Sustainable Development Goals came to the fore as a political commitment for many countries, one of the goals of this very important approach was to try to eliminate viral hepatitis by 2030 . However, although the neighbouring country of Afghanistan is the largest producer of narcotics, and considering the large volume of immigration into Iran and related risk of injecting drug use in young people and consequent increased incidence of hepatitis C, Iranian policy-makers still do not consider this evidence to be a major issue for hepatitis $C$ risk in the country [26].

Each year, new issues and problems arise in the Iranian health system, with various responses from policy-makers, but many problems remain unsolved. This again reinforces the importance of EIPM and the need to institutionalize this approach in the Iranian health system [6]. In general, discussions of the practical application of evidence in health policy have been less extensive, and there has been very little discussion about Iran in the literature. Also, there is no comprehensive evidence on how to strengthen individual and institutional 
capacity to develop EIPM in Iran. Thus, it is necessary to strengthen mechanisms that can promote knowledge and skills among researchers and knowledge-producing organizations in establishing EIPM. In this regard, the interventions need to be focused on both the individual and institutional level. Therefore, this study aimed to review the interventions used to promote researchers' and knowledge-producing organizations' knowledge and skills in the production and translation of evidence to policy-making, and to explore the interventions for strengthening EIPM at the individual and institutional level in the Iranian health system.

\section{Methods}

Review and qualitative methods were used to conduct this study, which was carried out in two phases. In the first phase, we conducted a systematic review to collect interventions on increasing individual (researchers) and institutional (knowledge-producing organizations) knowledge and skills in the production and translation of evidence to policy-making.

In the second phase, we conducted a qualitative study to explore Iranian health system experts' viewpoints regarding necessary interventions in the Iranian health system for implementing the collected interventions to empower researchers in moving towards establishing EIPM in Iran.

\section{The review phase}

In order to maintain the integrity of all stages of this study, the Preferred Reporting Items for Systematic Reviews and Meta-Analyses (PRISMA) guidelines were followed [27].

In response to the study question-what interventions are available to increase the knowledge and skills of researchers in producing and translating evidence needed for health policy-making-a systematic review was chosen. This type of review study helps to establish the foundations for developing evidence-informed decision-making and identifying knowledge gaps and finding topics for future research. The results of these studies have high validity due to the specific method and quality of the studies and can be beneficial for all stakeholders in the health system [28].

\section{Inclusion criteria}

In the context of this article, based on the research question, inclusion criteria were identified by the research team. Our inclusion criteria were as follows:

(i) Studies addressed a variety of educational programmes and interventions used to train and increase the use of EIPM in the health system. (ii) Studies were in the English language.

(iii) Studies were published between 1992 and the end of 2019.

(iv) A variety of studies were reviewed, including systematic reviews, narrative reviews, original research, commentary, letters and editorials.

(v) Studies were published in peer-reviewed journals.

\section{The literature search}

Reference lists of included studies were reviewed and scanned for possible relevant studies, attempting to keep the results up to date while writing the article. Scopus and PubMed were searched. The search strategy and results for each database are listed in Additional file 1: Appendix $1 \& 2$. The search was carried out by two members of the research team (LD and EH). In order to increase the validity of the study, a review of articles at each stage was performed by two members of the research team (HM and $\mathrm{EH})$, and the degree of agreement between them was assessed. In cases where agreement was not reached between the two researchers, a third researcher was used. In addition, during a meeting with the research team, consensus was reached on articles that were considered contradictory.

\section{Data extraction}

To extract the data, a researcher-designed form was used that included the most important characteristics of the papers, as follows: first author, year of publication, the purpose of the training programme, method of training, data collection, country, main findings, method for enhancing practical skills, specifications of curriculum, the content of the audience training, the credentialling organization and the curriculum evaluation.

\section{Quality assessment}

Due to the wide range of final studies, appropriate Joanna Briggs Institute checklists were used to evaluate the quality of the final studies. The institute has dedicated checklists for each type of study. The quality of studies was classified into three categories: good, moderate and poor.

\section{The qualitative phase}

The COREQ (Consolidated Criteria for Reporting Qualitative Research) checklist was followed for the qualitative reporting phase. In this qualitative study, data were collected through interview and documentary review. Semistructured interviews were used to collect the opinions and experiences of key health experts regarding capacity-building among researchers and knowledge-producing organizations in the production and translation 
of evidence required for policy-makers and providing appropriate empowerment programmes in Iran.

\section{Study participants and data collection}

Participants including researchers, health policy-makers, health planners and faculty members were selected from various institutions through purposive sampling. Documents were also selected from various relevant organizations including health research centres and institutes, faculties and health broker organizations. Purposive sampling was conducted using the maximum diversity method to select research participants. Sampling was continued to reach saturation. Inclusion criteria for participant selection included individuals with experience in EIPM such as publishing papers, reports or projects. Interviews were conducted in the participants' office or the place that they preferred. Before starting the interview, informed consent forms were completed by the participants. We assured participants that they could exit the study at any time. Interviews were conducted based on an interview guide which we developed according to the study objectives covering two types of information including demographic questions and the main questions of the study. To finalize the interview guide, three preliminary interviews were conducted. The interview guide is provided in Additional file 2: Appendix 2. Four interviews were conducted by sending an email to the participants and asking them to write their answers on the paper or record their answers to the questions.

\section{Data analysis}

Each interview was transcribed verbatim. To improve the rigour of the study, various activities were carried out. To increase credibility, dependability, conformability and triangulation, we used several resources for data collection, including conducting interviews with various participants and conducting document reviews. After interviews, transcribed files were sent to participants for confirmation or to make any changes they wanted. To increase transferability, purposive sampling was used. Data were analysed according to a five-stage thematic framework approach, including familiarization, identifying a thematic framework, indexing, charting, mapping and interpretation.

\section{Results}

The results of our study are provided in two main parts: the review phase results and the qualitative phase results.

\section{The review phase}

Our search yielded 11,514 articles, 10,414 of which remained after deleting the duplicates. Following the secondary screening and examination of the articles' full texts, 18 articles remained. The PRISMA flowchart of the study's articles is illustrated in Fig. 1.

The characteristics of the included studies are presented in Tables 1 and 2. Most of the studies were from Nigeria, among which six were by one author and his colleagues. Other studies were from Canada (three studies), Australia (two studies), Mexico, England, Fiji, Hungary, Belgium, South Africa and the European Union. Interventions were performed over periods ranging from 1 day to 3 years. In the study by Uneke et al. in 2012, a 1-day workshop was used for training [29], while in the study by Dreisinger et al. in 2008, online training was conducted from 2001 to 2004 [30]. The studies reviewed were published in different journals. The largest number were in Health Research Policy and Systems, with three studies published. The other journals included the Pan American Journal of Public Health, International Journal of Technology Assessment in Health Care, Healthcare Management Forum, BMC Public Health, Evidence \& Policy, Energy Strategy Reviews, Public Health, Global Public Health, Journal of Health Services Research \& Policy, and Health Policy.

Most studies used a mix of quantitative and qualitative methods $[31,34,46]$ for data collection and analysis. Studies showed that a series of interventions including workshops [14, 47], online training [30, 48] discussion sessions, email training $[43,49]$ and websites were used to train EIPM. In most cases, questionnaires were used as pre- and post-tests to compare the effectiveness of educational interventions.

In some studies, to assess the impact of the intervention on researchers' and policy-makers' knowledge, their performance was reviewed at the end of the course to quantify their use of scientific evidence in their day-today practical decisions as well as their ability to formulate policy briefs. Evaluation of the results of the interventions in all studies showed a positive effect of the interventions on increasing the knowledge of the participants in the educational courses.

\section{The qualitative phase}

In total, we conducted 18 interviews. Table 3 shows the positions and characteristics of the participants. The interventions for capacity-building to strengthening EIPM were provided at the individual and institutional levels (Table 4).

\section{Institutional interventions}

Institutional interventions are categorized into: training programmes, knowledge management and institutional communication management, and research cycle management. 


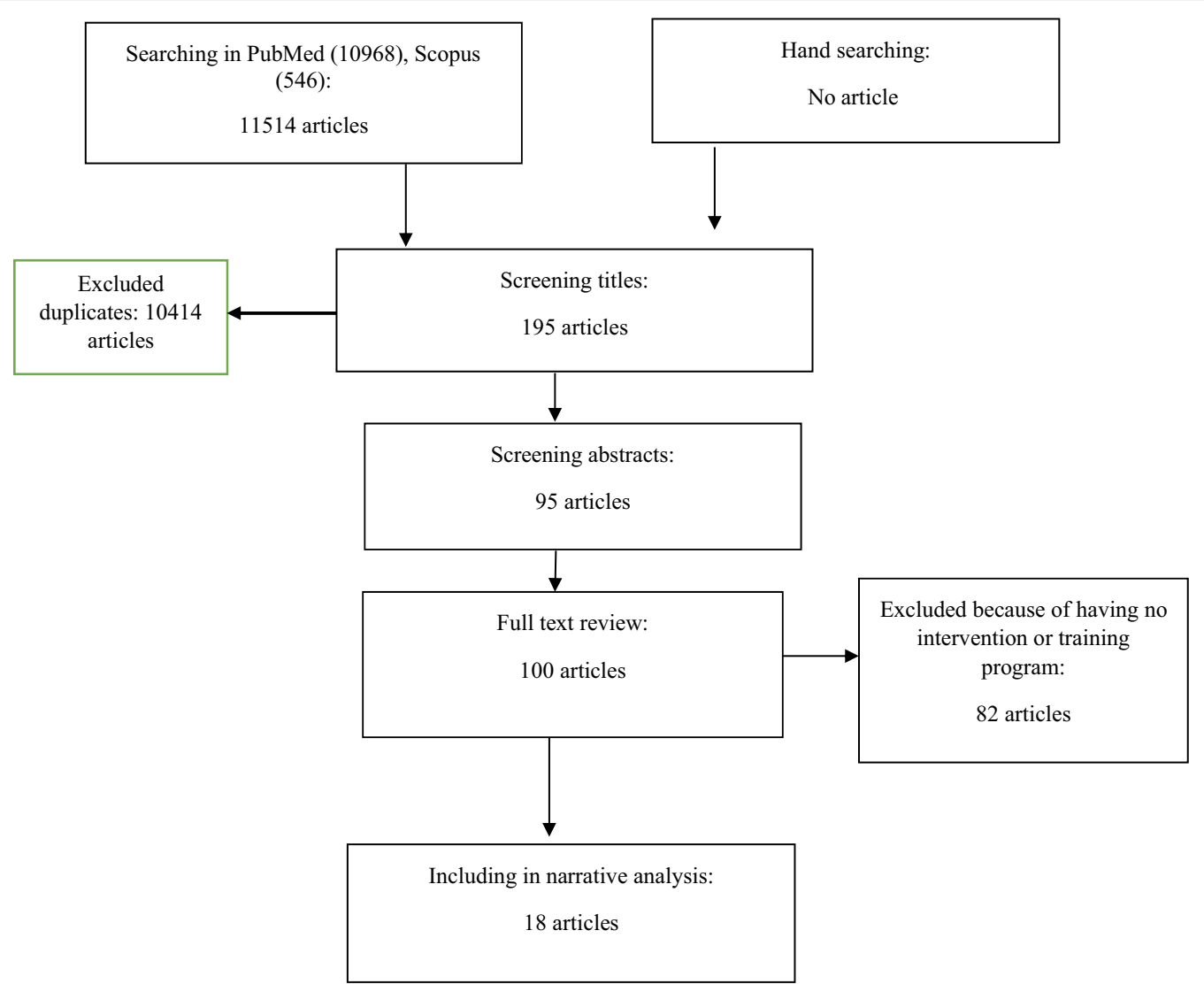

Fig. 1 Selection of studies for review analysis

\section{Training/courses for researchers}

Review of the documents and analysis of interviews indicated that one of the most important measures for capacity-building among researchers and knowledgeproducing organizations is holding relevant specialized training programmes or courses.

According to some of the participants, the use of shortterm specialized training programmes which can be defined at the institutional level is a highly effective educational method. The nature of these programmes and the course subjects and content will help researchers and others involved in knowledge production to develop the required skills allowing them to meet the needs of policymakers. In most cases, short-term training programmes are designed and implemented for two main reasons: to teach scientific and technical skills and to change organizational behaviour.

It's necessary to assess the needs of the consumers of knowledge products and develop training programmes accordingly. (interviewee 9 [I-9])

The use of modern teaching techniques such as distance education and designing and planning the training programmes based on policy-makers' expectations were other issues raised by the study participants.

\section{Knowledge management and organizational communication management}

According to the interviewees, in the context of EIPM, knowledge management is a systematic approach to understanding and using knowledge or information and making it available to policy-makers at the right time, thus allowing them to make informed decisions. The findings of the present research indicate that achieving EIPM requires knowledge management to be focused on projects and knowledge development, establishing the relevant knowledge base, the exchange and sharing of knowledge among the employees of the organization, and training.

There should be a system in place for registering policy researchers and monitoring their scientific and professional activities. (I-1) 


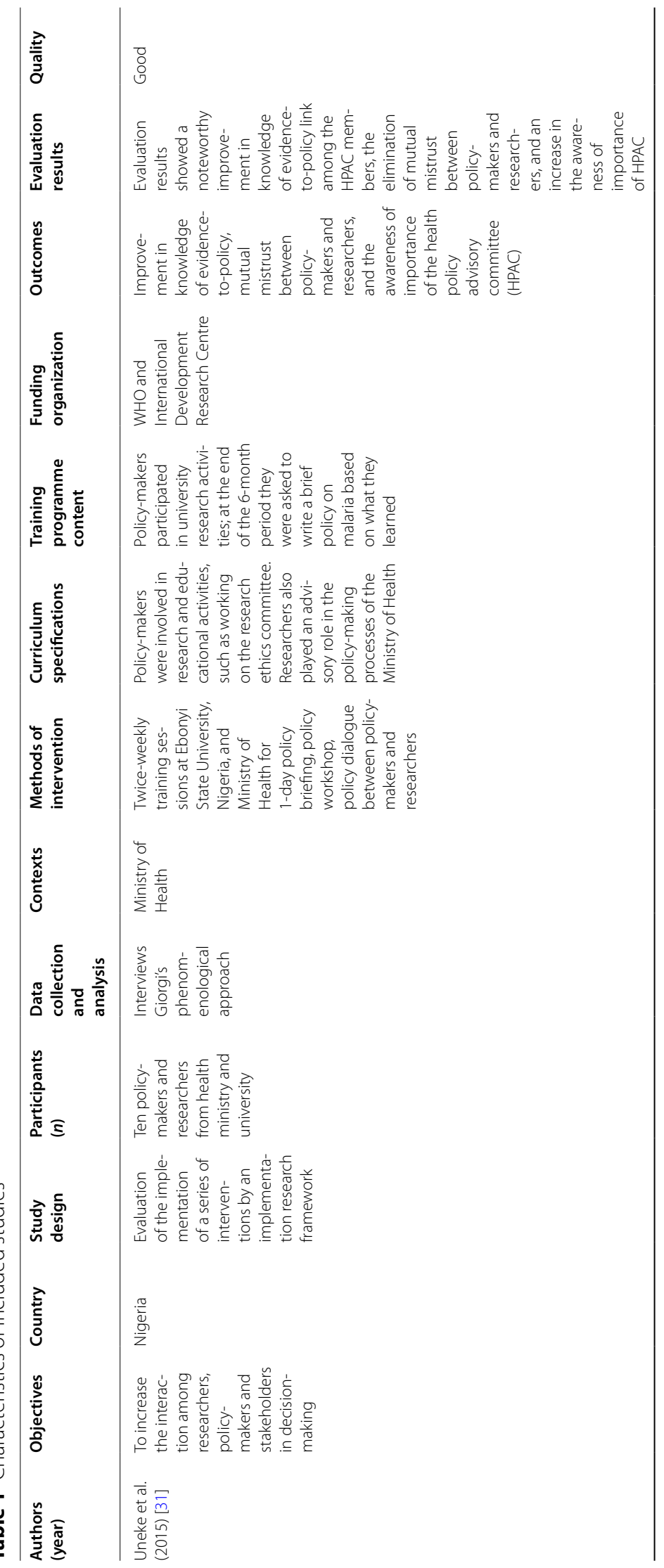




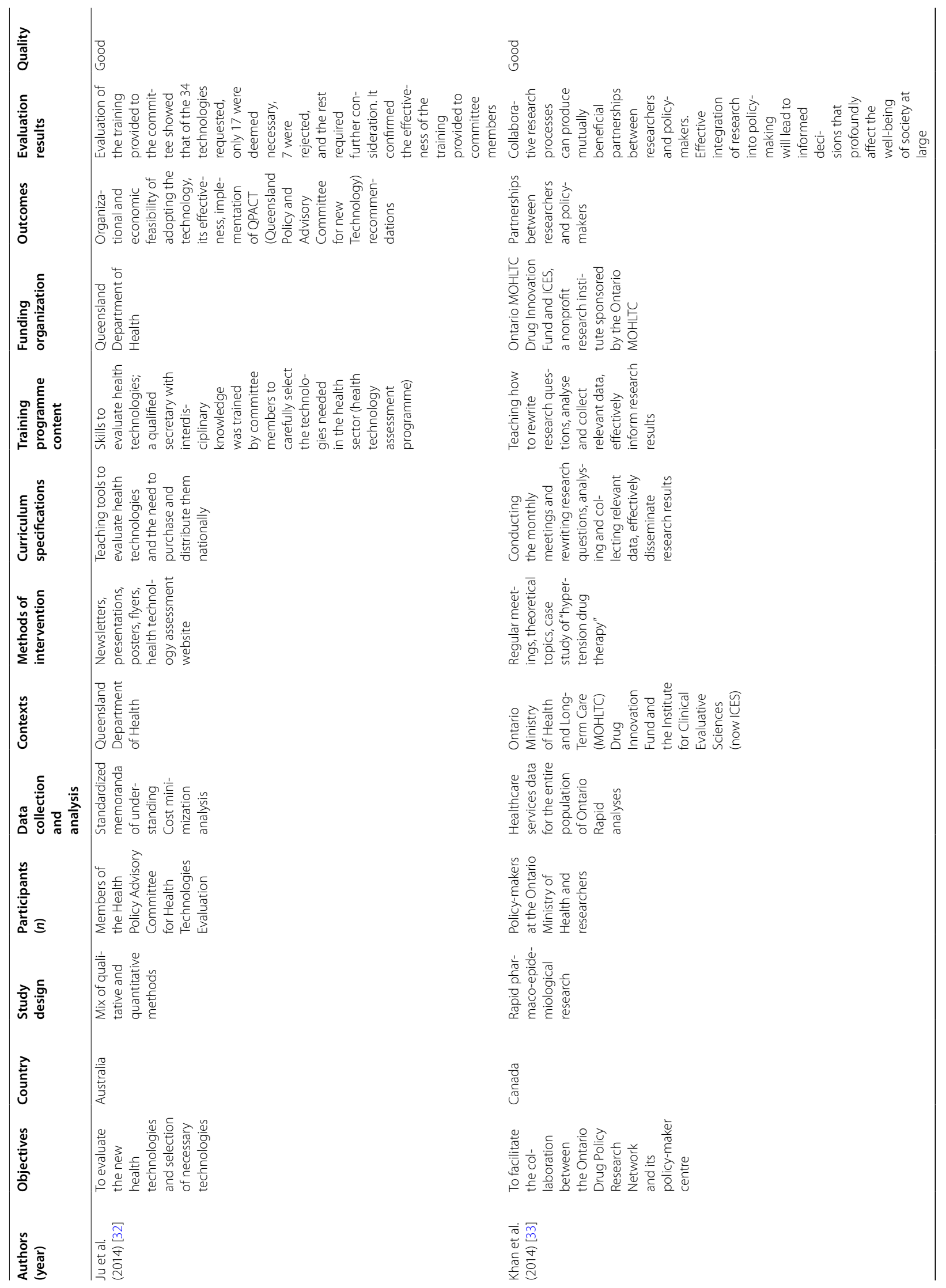




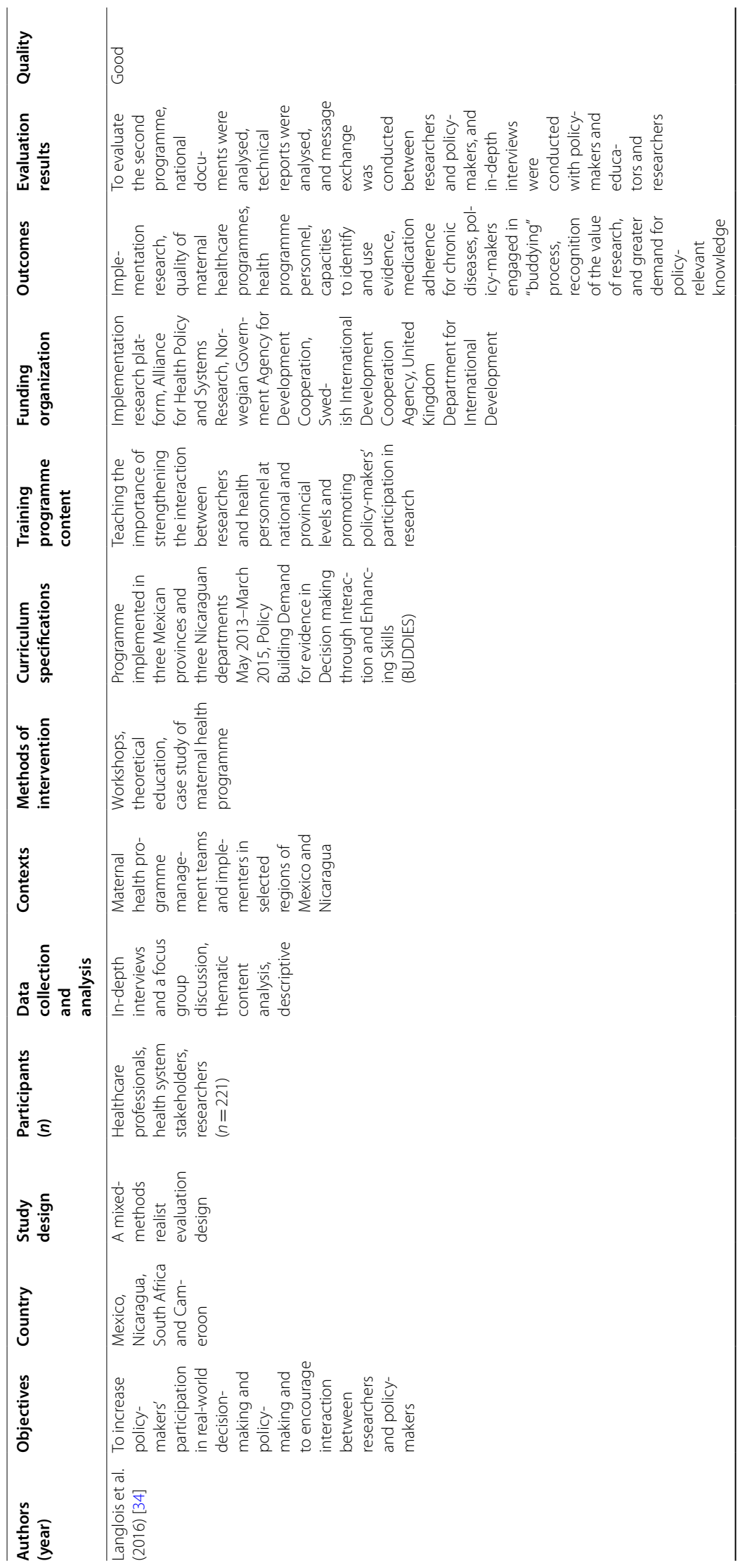




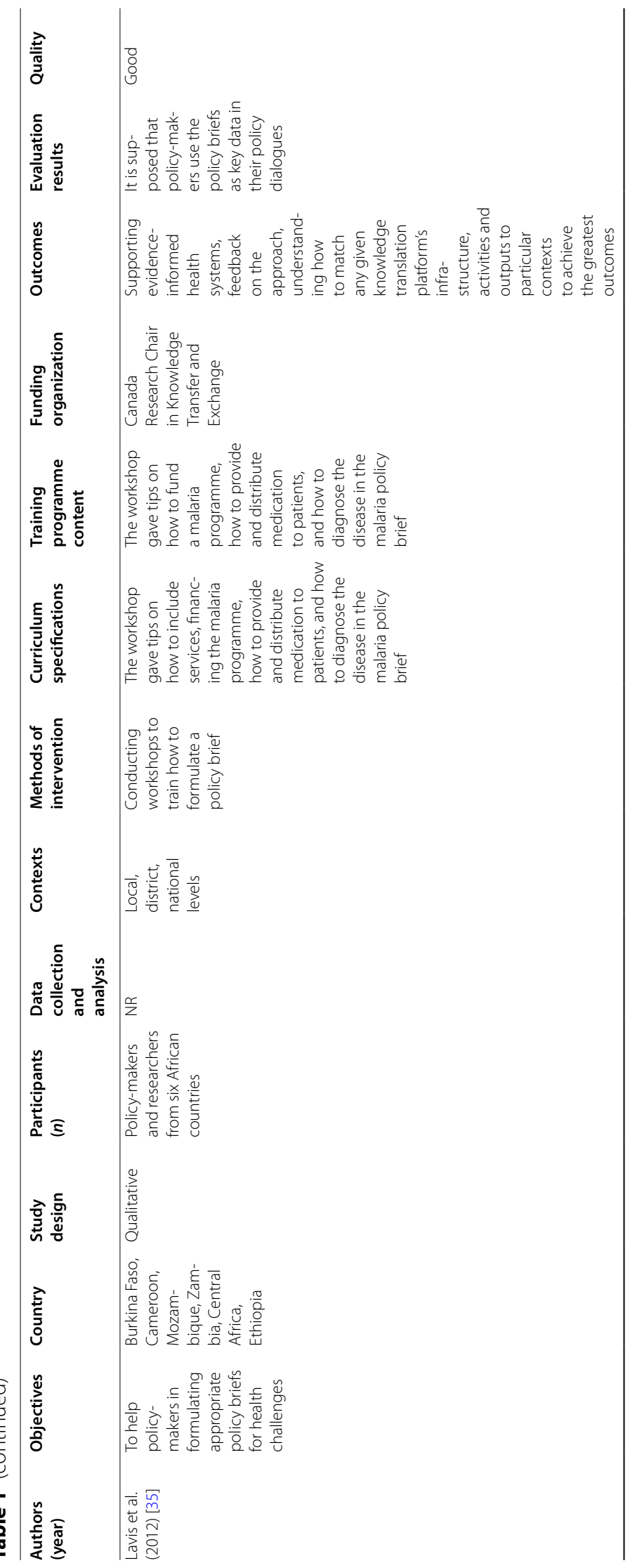




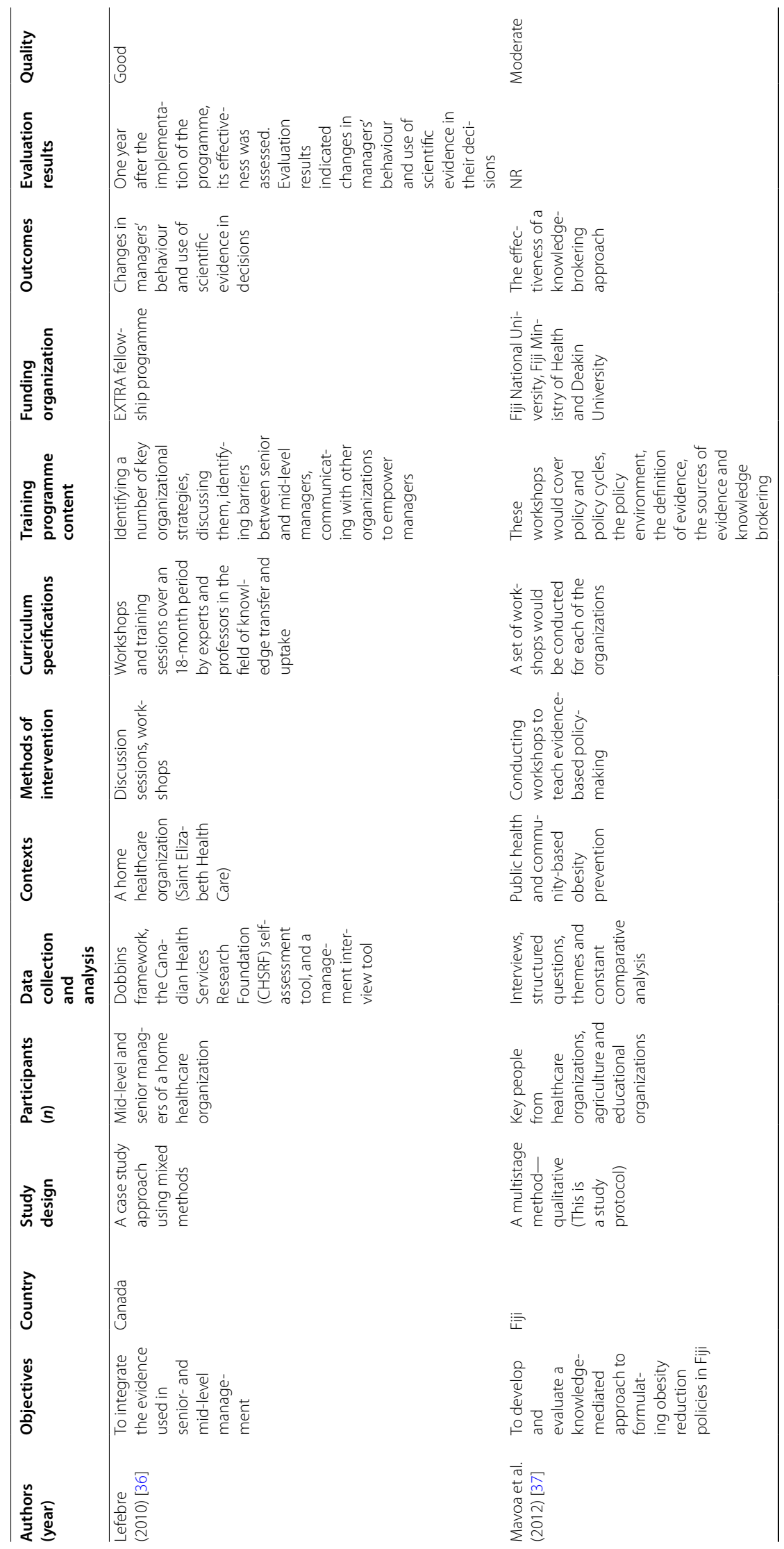




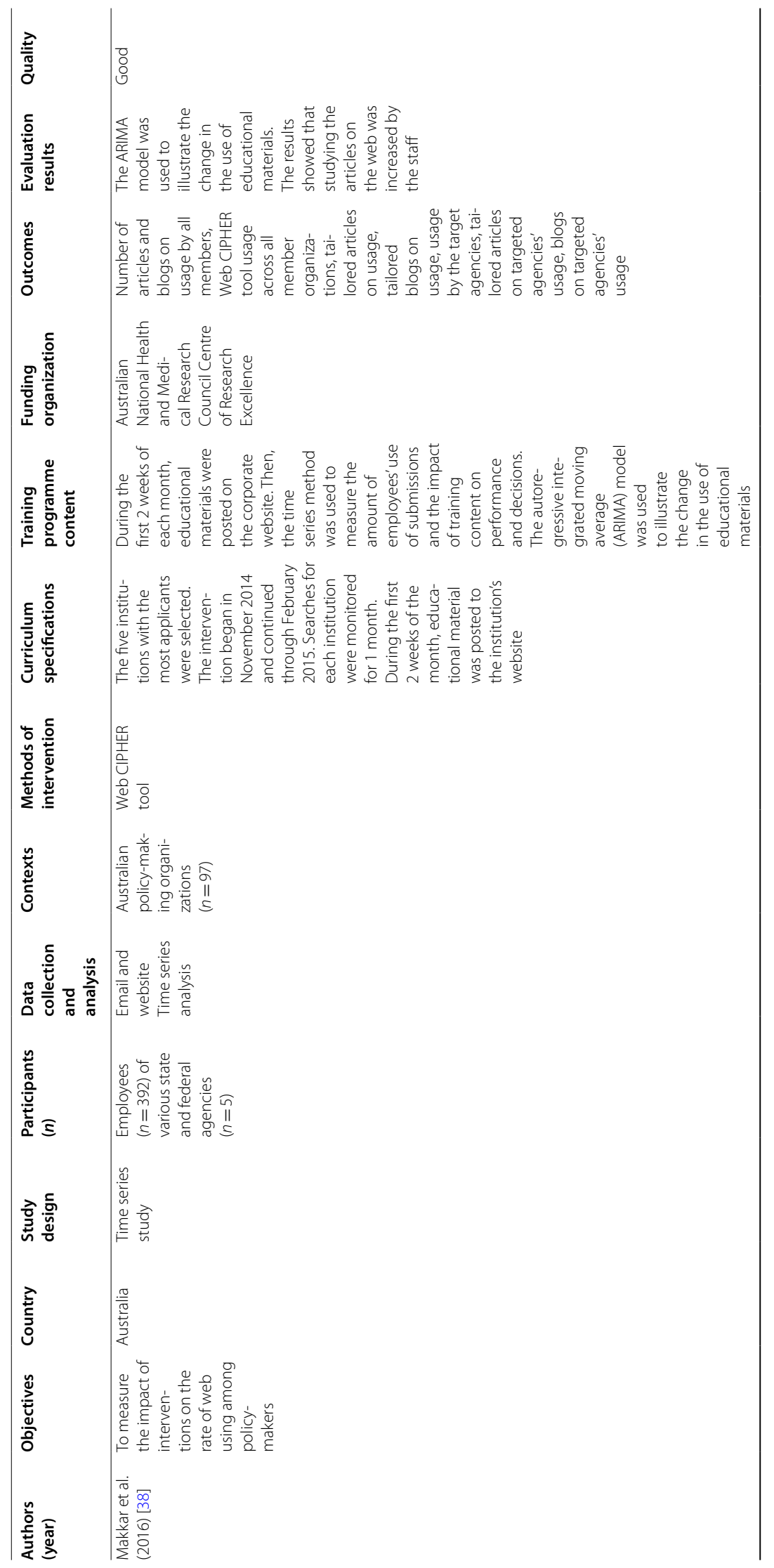




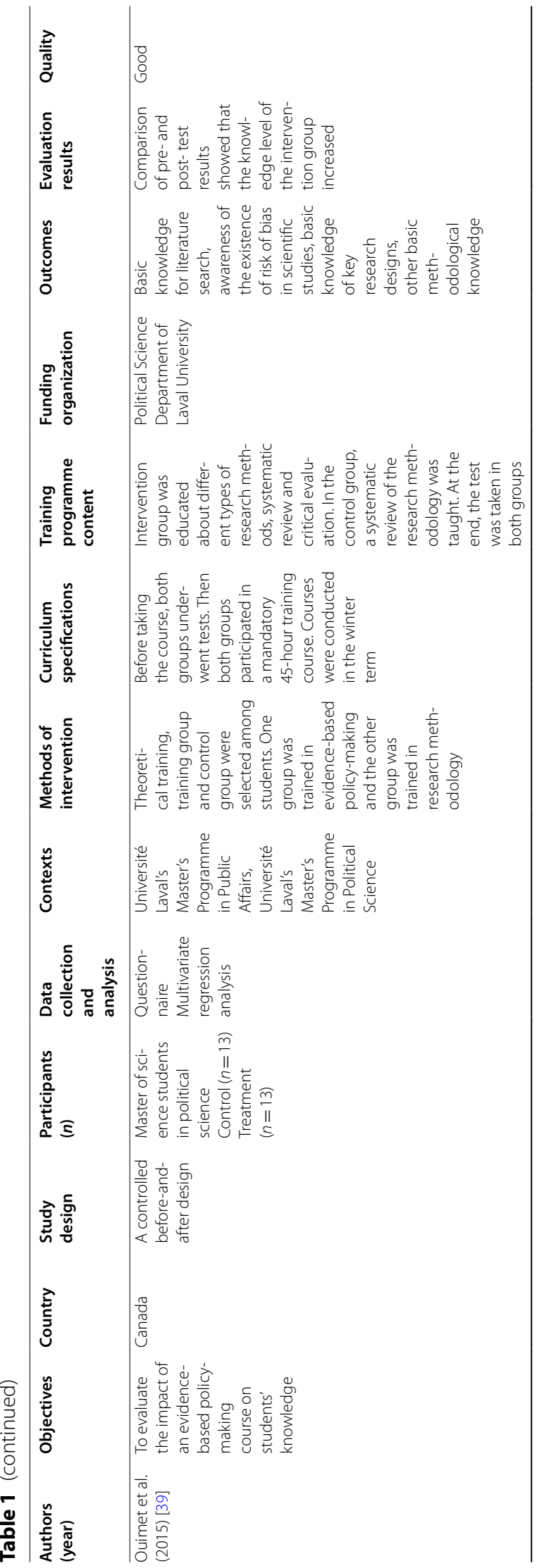




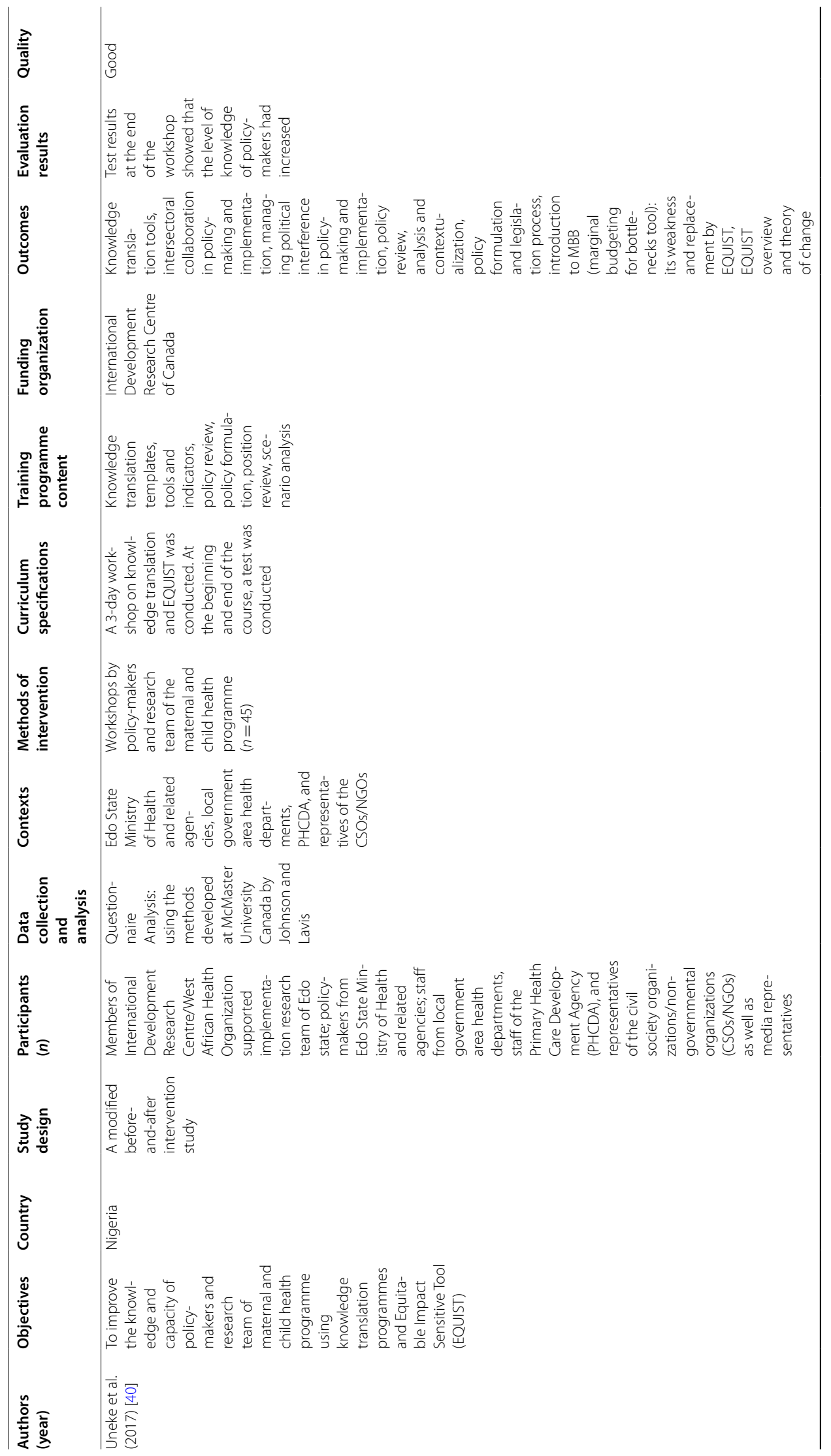




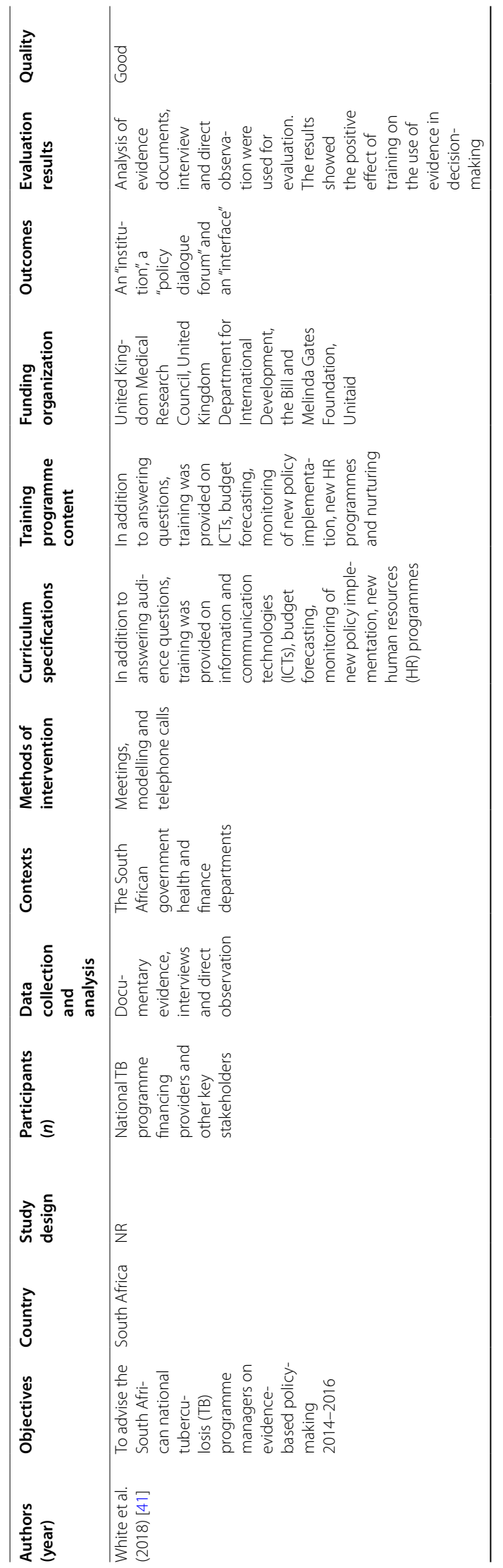




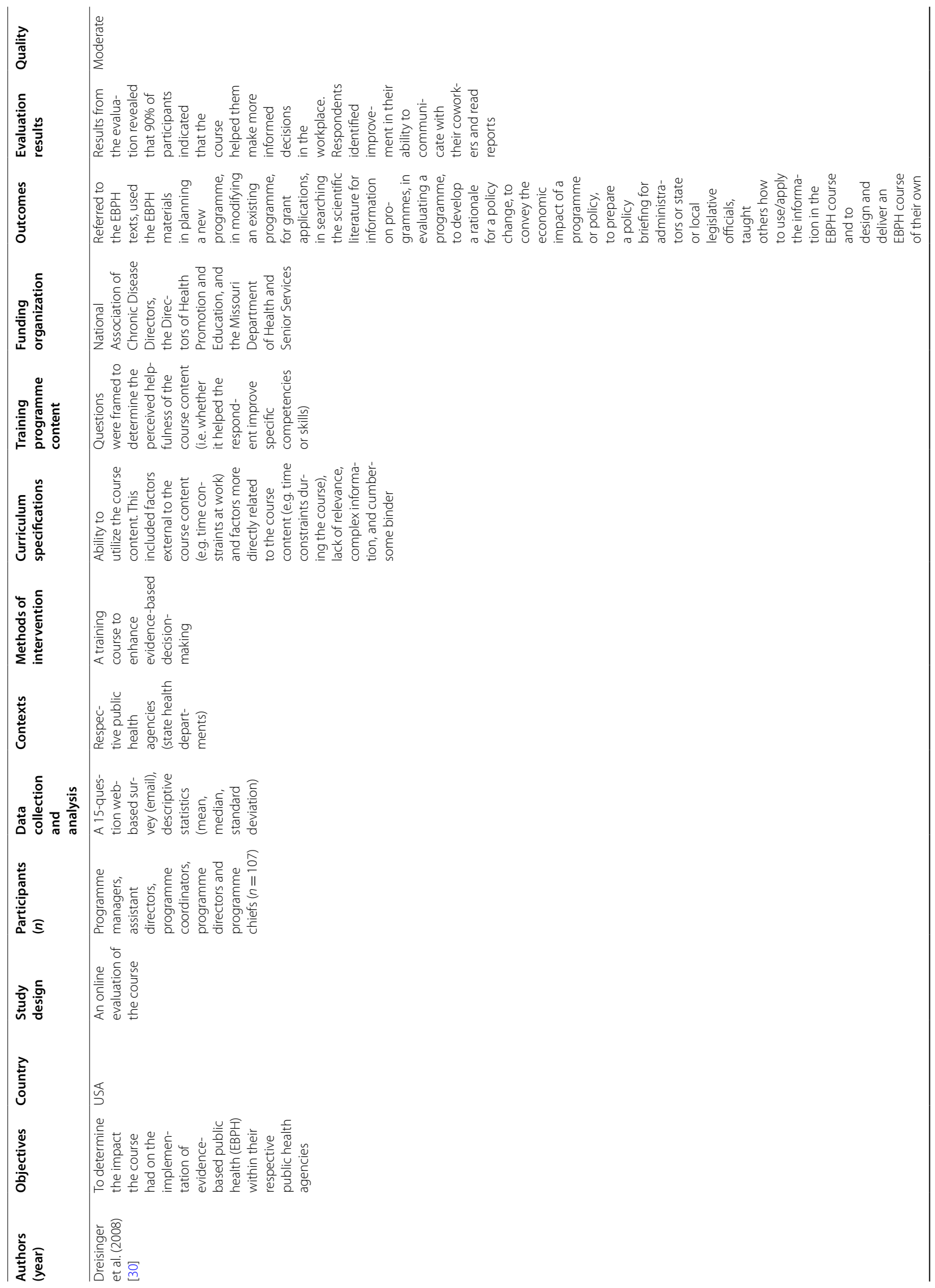




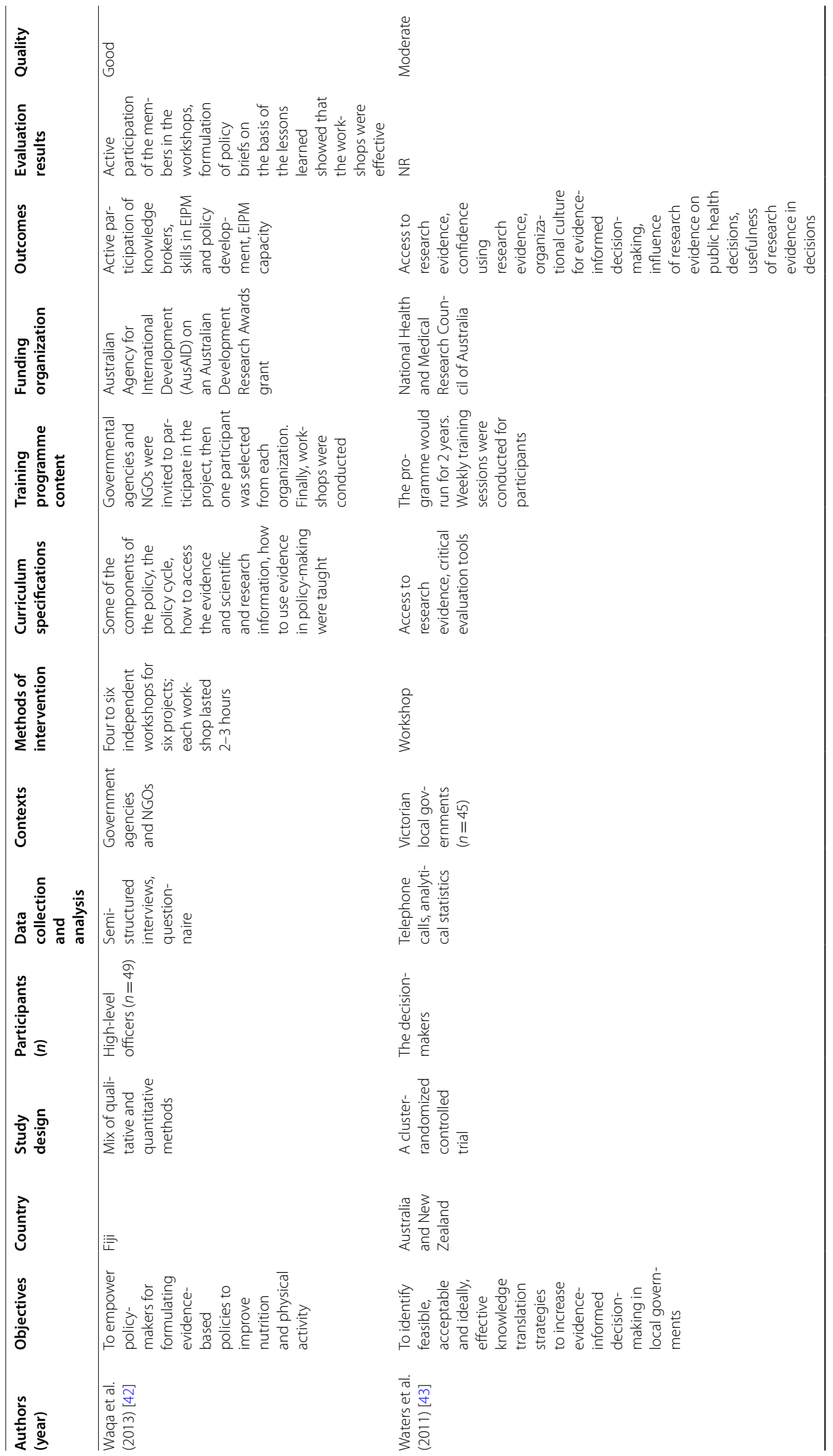




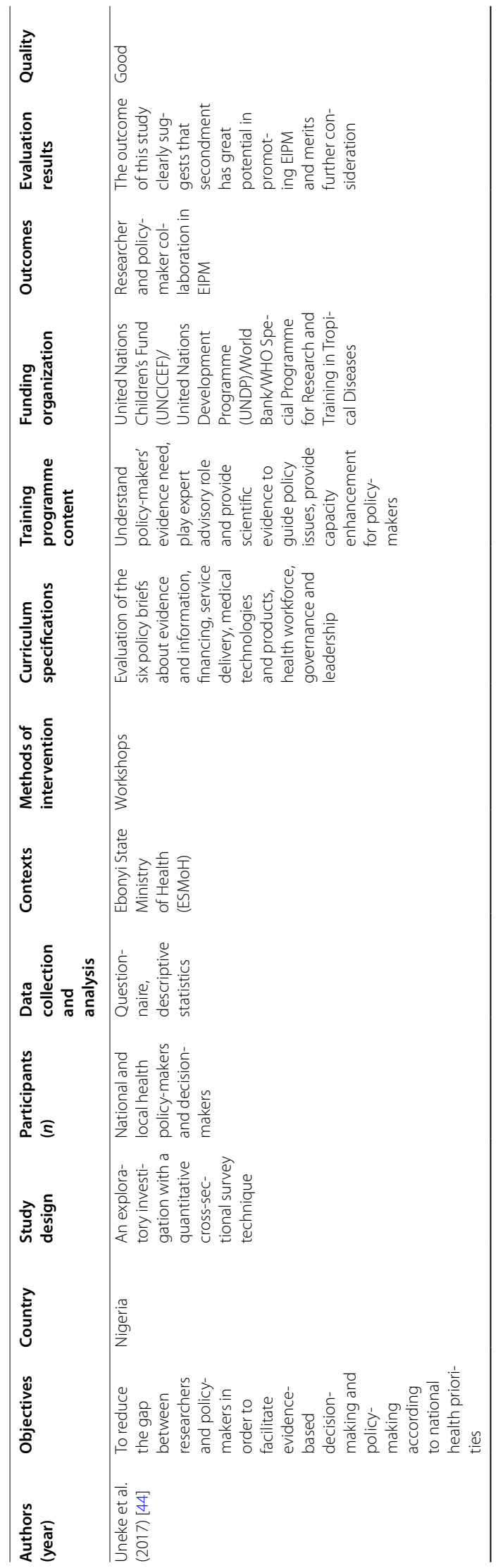




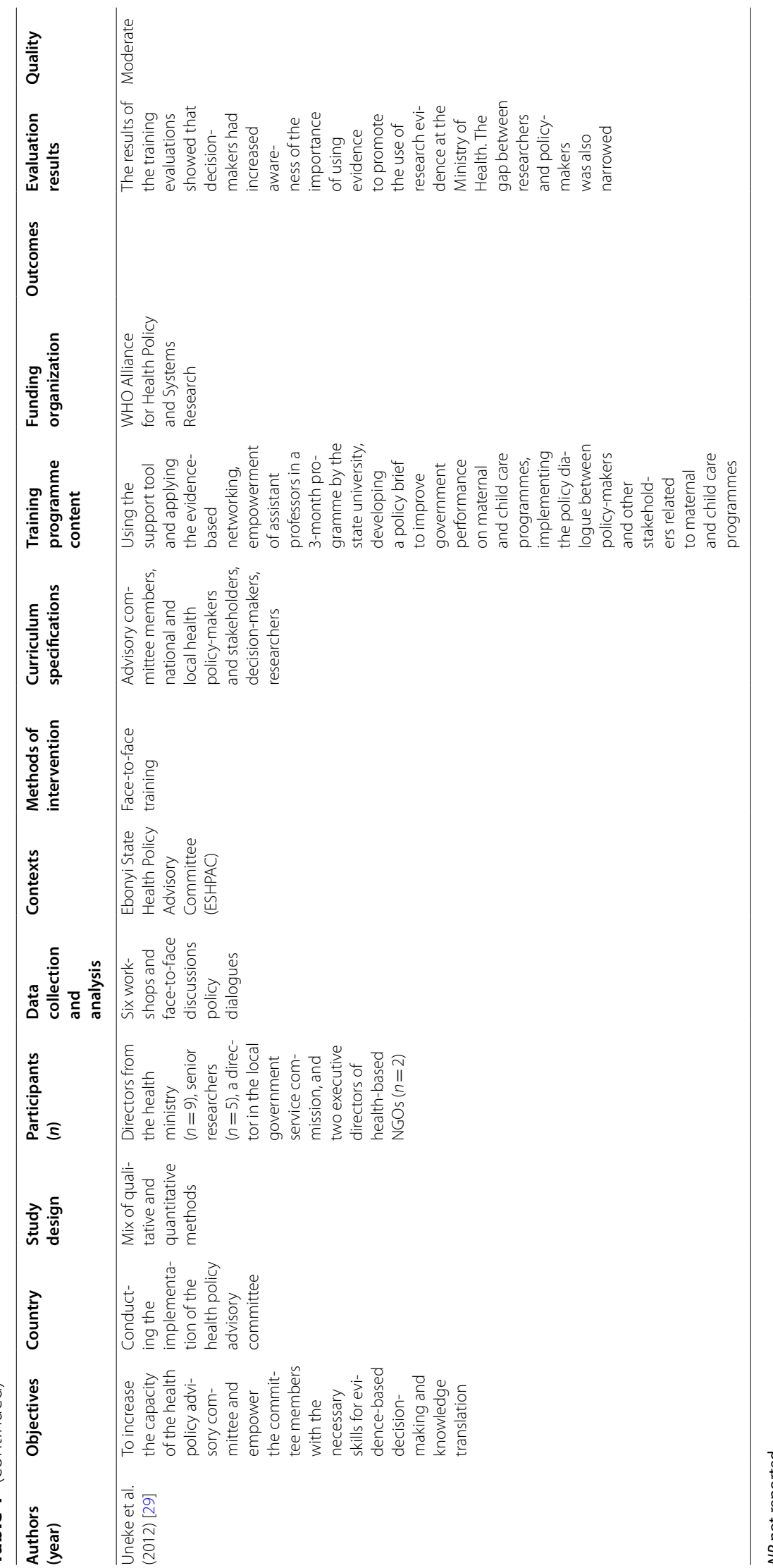




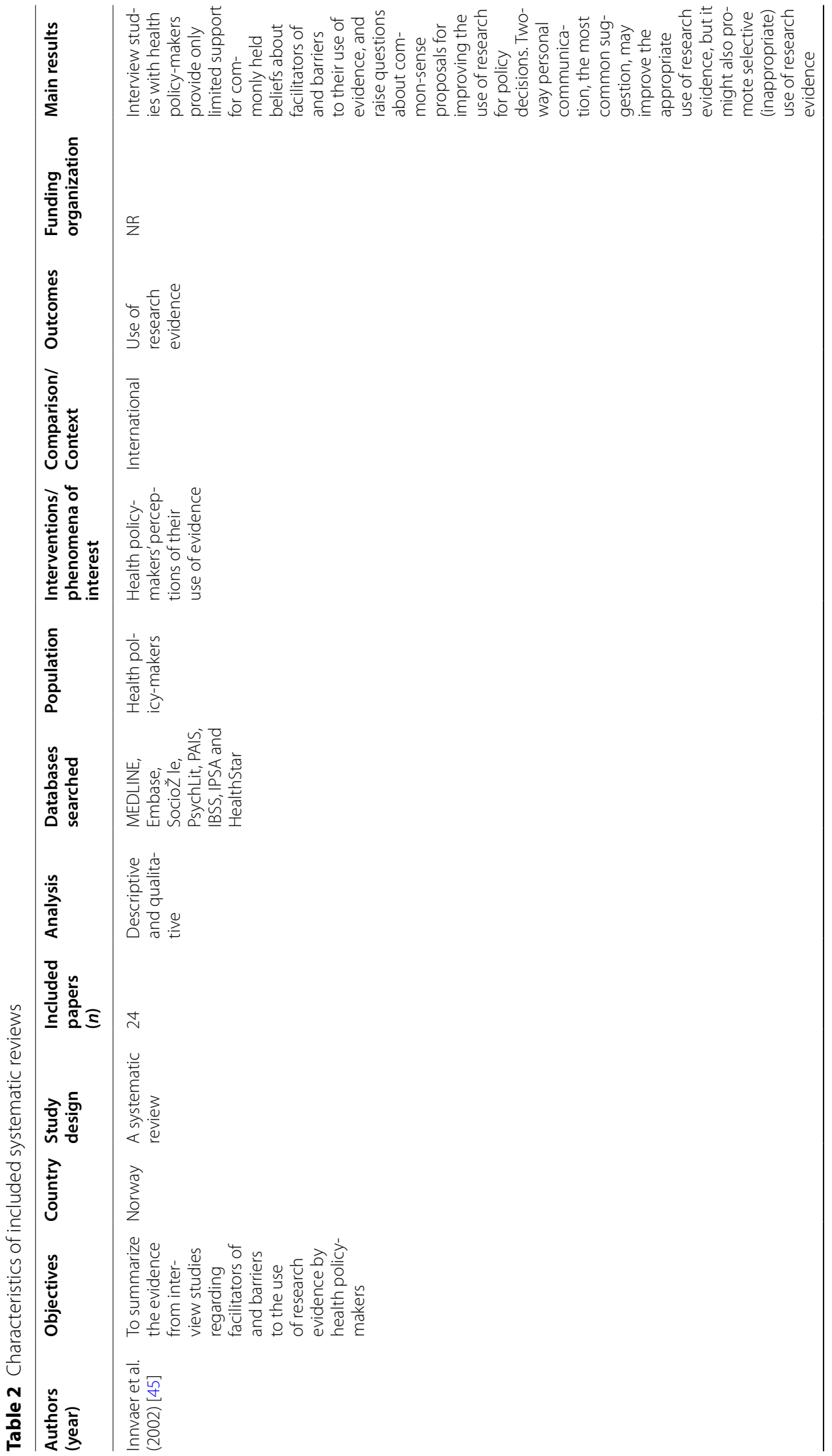




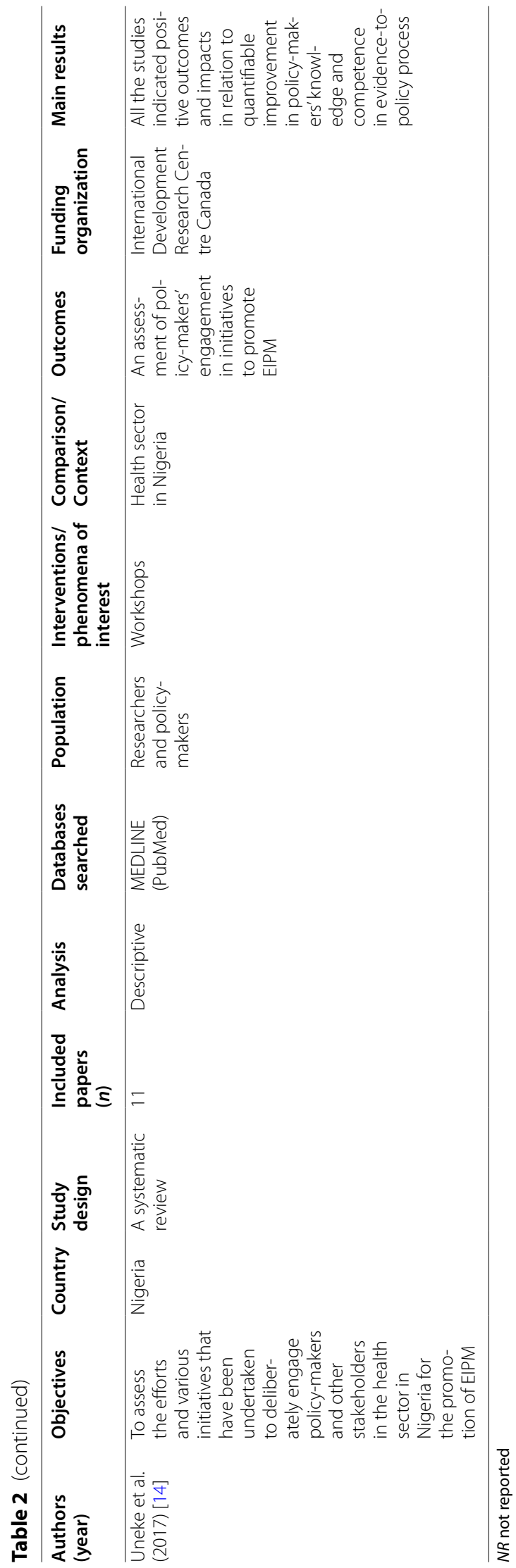


Table 3 Characteristics of interviewees

\begin{tabular}{llllll}
\hline Organization & $\begin{array}{l}\text { Number of } \\
\text { participants }\end{array}$ & Sex & & Academic discipline \\
\cline { 4 - 5 } & & Male & Female & & $\begin{array}{c}\text { Health policy } \\
\text { disciplines }\end{array}$ \\
\hline Health research centres & 2 & 0 & 2 & 1 & 1 \\
Health research institutes & 2 & 1 & 1 & 0 & 2 \\
Research units of the Ministry of Health & 4 & 1 & 3 & 2 & 2 \\
$\begin{array}{l}\text { and Medical Education } \\
\text { University of medical sciences }\end{array}$ & 13 & 3 & 7 & 5 & 5 \\
Total & 18 & 5 & 13 & 9 & 9 \\
\hline
\end{tabular}

\section{Research cycle management}

Effective research cycle management is an important consideration in interventions for empowering researchers to strengthen EIPM. The research cycle begins with the proposal of a research idea and design, and continues until evidence production and application. By focusing on the production of credible evidence, effective research cycle management leads to the identification of more influential and higher-quality research and lays the groundwork for better use of evidence by users such as policy-makers.

It's especially important to pay attention to the qual-

ity of data produced in organizations. (I-12)

The findings indicated that research cycle management emphasizes the adoption of strategies for directing knowledge creation towards more influential and higherquality research and preventing the unhindered publication of "pseudo-research".

Evidence production networks in the country are faced with poor management. For example, research priorities in the networks of the Ministry of Health and the way these priorities are established are unclear. (I-14)

\section{Culture change}

The interviewees believed that evidence-based health interventions and policies must be promoted and accepted by all stakeholders. If this becomes the prevailing practice, it will lessen the impact of conflicts of interest and political inclinations on decision-making.

We all know the significant impact and role of pressure groups in the world of policies. We must force policy-making toward demanding appropriate evidence from researchers and research centres. Once we build this culture, researchers and knowledge producers will also have to improve to keep pace with policy-makers' demands. (I-7)

\section{Evaluation and assessment}

According to many of the interviewees, changing the evaluation and assessment system, defining motivators, changing the reward system, especially for faculty members and researchers with respect to policy-focused knowledge translation, and changing researchers ranking method in the Research Department of the Ministry of Health play a significant role in the promotion of this policy approach.

An issue that must be addressed is the evaluation system. Faculty members and students are only concerned with producing articles, not being responsive to the needs of different groups and the society as a whole. (I-10)

\section{Individual interventions}

Behavioural-motivational interventions Motivational interventions play a key role in the performance of researchers and knowledge-producing organizations and are critical to strengthening EIPM. Knowledge about the personal characteristics of individuals in an organization and the use of various motivators will enable them to communicate more effectively with their audience and strengthen this policy approach. Designing the educational courses based on researchers' needs, asking them to present their personal interests in research fields, and asking them to assume a main role in the training courses can motive them to act beyond what is expected.

As a researcher, I would like to be given the opportunity to study in other countries, because it will increase my knowledge, and as a result I will be able to do better researches on issues related to the health system. (I-7)

Moreover, demonstrating the key role of researchers in developing the organization's plans will motivate them in future activities. 
Table 4 Themes and subthemes of interventions for individual and institutional capacity-building to strengthen EIPM

\begin{tabular}{ll}
\hline Theme & Subtheme \\
\hline Institutional interventions & Training \\
& Knowledge management and organizational communi- \\
cation management & Research cycle management \\
& Assessment and evaluation \\
& Culture change \\
Individual interventions & Knowledge of policy-making and policy analysis \\
& Behavioural-motivational interventions \\
& Knowledge of policy evidence production and translation \\
& Knowledge of scientific communication \\
& Knowledge of the health system
\end{tabular}

We as researchers expect to be educated according [to] our needs, we want to know about the complicated entity of the health systems, and we also like to know what exactly health policy-makers expect of us. We want to have a common language to have a better [understanding] of community's needs. (I-10)

According to many of the participants, multidimensional behavioural-motivational interventions have a significant effect on individual performance.

It may seem strange to you, but sometimes giving a small gift or even a credit card increases our motivation to participate in training courses. (I-13)

Knowledge of policy-making and policy analysis According to the interviewees, one of the issues that is often ignored with regard to strengthening EIPM is the considerable gap between the world of research and the world of policy-making, which acts as a major barrier to expanding this policy approach. To reduce this gap, researchers and faculty members need to become familiar with the basic concepts and principles of policy-making and policy analysis and apply them in their research endeavours.

Individuals and organizations that seek evidenceinformed policy-making must possess both policymaking and evidence-related knowledge. (I-3)

The participants believed that problem for science and evidence-based policy comes when politicians and other political actors decide to discredit the science on which a conclusion is based or bend the science to support their policy position. This is called policy-based evidence as opposed to evidence-based policy. Researchers who possess the knowledge of policy-making can prevent this and use policy-makers' language to promote EIPM.
Knowledge of policy evidence production and translation The interviewees were of the opinion that the gap between the knowledge produced by researchers and organizations and the decisions and policies made by senior officials is a key challenge in the implementation of EIPM. Interventions are needed to bridge this gap, including the provision of skills and knowledge of policy-related evidence production and translation. An understanding of knowledge translation was highlighted by the participants as a key factor in strengthening the adoption and application of research results by policy-makers, which will enable them to make informed, knowledge-based decisions and policies.

Instruments that can contribute to informed policymaking and decision-making and translating evidence into the language of policy-makers aren't used extensively. Policy-makers don't receive the necessary skills. Employees almost never reach the level of knowledge translation in evidence-informed policymaking and remain at the level of producing articles, mostly at the national level. (I-5)

Knowledge of science communication Communicating science to policy-makers is one of the skills that was underscored by the interviewees. They argued that science communication must be in both oral and written format. The use of instruments in the language of policy-makers can attract their attention to a specific problem and prompt them to implement appropriate interventions.

In our country, there is a weak link between knowledge producers and policy-makers. Each policymaker must be guided by a number of researchers. We can argue that these two groups are still in dire need of better communication. (I-14) 
According to the participants, familiarity with the characteristics of research data users (i.e. policy-makers and decision-makers) and the nature of their work allows for establishing more effective science communication, conducting research with the participation of decisionmakers, and identifying the social barriers to changing evidence users' behaviour.

Knowledge of the health system To institutionalize and strengthen EIPM, researchers and knowledge-producing organizations need to understand and be aware of the functions and goals of the health system, its different sections and components, how it affects and is affected by other sectors, and the history and outcomes of important actions and policies implemented within the health system. Some interviewees believed that issues such as systems thinking and systems dynamics can also be influential in a better understanding of the outcomes and effects observed within the health system and using this knowledge to inform policies.

\section{Discussion}

The institutionalization of EIPM in any country is a complex and complicated process and requires various initiatives both among policy-makers (pull side) and researchers (push side) and in the health system and the health system policies and plans $[6,22]$. This study focused on developing evidence-based and context-aware policy interventions for increasing the capacity of individual and institutional capacity-building for EIPM in Iran.

Developed countries have a long history of policymaking based on evidence, but a review of the studies showed that even countries such as Canada, England and Belgium have continuing programmes for training and updating health policy-makers in order to apply evidence in decision-making. Studies showed that one of the main dreams of researchers is to increase the application of evidence in decisions and policies. To make this dream come true, they have been conducting various interventions at the individual and institutional level.

One of the best means for capacity-building to strengthen EIPM is to conduct training courses using various methods. Training is a key step in developing a skilled workforce and a useful tool for improving the quality of policy-related research. Formal education in universities (e.g. through specifically designed courses and/or by including relevant discussions in other courses), shorter training programmes, workshops, and on-the-job training are some of the suggestions made by the participants.

According to the findings of our review, face-to-face workshops and policy briefing were the most commonly used interventional method. A possible explanation for this might be that the interactional nature of workshops makes them a popular method for training, especially in sessions with different groups of audiences. Also, this result may reflect the fact that the possibility for direct discussion and participation in topics accelerates learning by the audience.

Online training through a website or sending the educational material by email was the second most effective method. In this way, participants who could not participate in sessions at a specific time and place could benefit from online training. Moreover, the low costs and ease of online training could be a reason for the popularity of virtual training [38]. However, this method is limited for organizations with poor internet access, so high-connectivity internet must be available for all participants. The university course over several months that was held as an academic course was the third most common method. These courses are useful, but it seems that developing a suitable long-term programme, adequate budget and interested audiences are essential for successful conduction of the training [50]. Of course, online implementation of these courses can allow researchers and policy-makers in low- and middle-income countries (LMICs) to spend less time and money while obtaining useful knowledge about research and policy issues. However, one of the best ways for increasing audience empowerment and knowledge is to conduct training courses through diverse methods [51]. It seems that applying several methods increases the influence of training [52].

The results of the interviews showed that the combination of knowledge management and organizational communication management is a good option for presenting and disseminating the best and most appropriate knowledge within the organization. Training is an essential element and an indispensable part of the human development activity in this regard. Our findings indicated that providing researchers and knowledge-producing organizations with relevant training will help improve their attitudes and enhance their knowledge and skills, thus playing a key role in strengthening EIPM. Uneke et al. believe that holding training courses is a major step towards bridging the gap between research and practice and strengthening EIPM $[47,53]$. Research management in the field of medical science requires managing and coordinating research activities, determining research priorities, formulating strategies and policies, and managing information [54].

Knowledge management and organizational communication management optimize the relationship between an organization or firm and its customers, partners and suppliers to maximize opportunities $[48,55]$. Production 
of knowledge and science is the main mission of universities and research centres, and this can only be achieved through research. However, it must be noted that being evidence-based is an essential characteristic of modern science. Research in the area of health policy-making is a systematic process for knowledge production to enhance the functions of the health system, including service provision, resource generation, financing and stewardship, and contributes to attaining its goals and ultimate objective, which is to enable all people to achieve their fullest health potential $[15,56]$.

Today, in order to ensure more successful implementation of EIPM, knowledge-producing organizations must pay special attention to knowledge management and organizational communication management, and must increase their communication with their audience, including decision-makers and policy-makers. Our findings highlight the importance of providing the right knowledge at the right time, that is, at the point of decision-making, by implementing knowledge management in healthcare organizations. Shahmoradi et al. [57] argue that it is very important to use appropriate tools and user-friendly systems for knowledge management, as this can significantly improve the quality of decisions made in various organizations $[58,59]$.

Issues related to research cycle management include developing strategies aimed at continuous and constructive cooperation for strengthening EIPM among knowledge producers (including researchers and knowledge-producing organizations) and knowledge users, providing support for policy-related data collection, archival, maintenance and distribution, and facilitating access to relevant data by users such researchers.

Researchers play a key role in exploitation of knowledge. Therefore, empowering them in knowledge exploitation activities is imperative [60]. A key requirement in these initiatives is taking measures for disseminating the knowledge obtained from research [61]. In this regard, one of the necessary interventions is to enhance the understanding of knowledge translation in this group. Knowledge translation includes a wide range of activities that can be used to effectively convey the message of the research to the target group (in this case, the policy-makers) $[62,63]$. Researchers sometimes tend to overestimate their knowledge translation activities, so it is necessary to train and familiarize them with all the aspects of knowledge transfer and translation as well as the methods for evaluating these activities, which can be highly effective in operationalization and use of research results [64]. Some studies showed that many researchers only seek to enhance the level of awareness among research audiences and stakeholders by relying on passive dissemination of knowledge, while paying little attention to changing users' performance and behaviour as the main goal of knowledge translation [19]. The findings indicate that strengthening EIPM requires researchers to continuously provide policy-makers with appropriate evidence-based insights and scientific advice to help them in their decision-making. However, a serious gap still exists in Iran, where researchers' recommendations do not produce desirable results, resulting in the adoption of inefficient and ineffective policies that fail to solve the general problems faced by the society and the health system.

Suggestions for the successful communication and operationalization of policy recommendations include the acquisition of knowledge related to policy-making and the translation of knowledge, including how to formulate and publish policy briefs or hold policy discussions, and how to identify and clarify policy problems [65-68]. Science communication is an important intervention for strengthening EIPM and was highlighted by many of the interviewees. It must be noted that science communication is not limited to empirical science, but also includes nonempirical reasoning (e.g. philosophy, techniques, and skills) [69]. The former can be acquired and is transferrable, but the latter is a larger part of knowledge that is intuitive and cannot be acquired. This form of knowledge requires special individual abilities and cannot be transferred to others $[70,71]$.

It appears that due to the absence of information on the topic of EIPM-related knowledge production and translation, there is little evidence on transferring tacit knowledge and converting it to explicit knowledge. Therefore, interventions for increasing the knowledge and skills of researchers and allowing them to strengthen EIPM have received ever-increasing attention in recent years.

\section{Study strengths and limitations}

The use of the two methods and collecting local and global evidence provided an in-depth view of the interventions for EIPM capacity-building. In addition, the level of detail that we found in qualitative research about interventions at the individual, institutional and health system levels is valuable. Some limitations need to be considered when interpreting the findings. Although the main focus of the review results is on the training and educational interventions at the individual and institutional levels, in the qualitative part of the study we also explored interventions at the community and the health system level. Due to a lack of sufficient evidence on the priorities of the proposed and implemented interventions for individual and institutional capacity-building, we tried to include all interventions that were effective. 


\section{Conclusion}

Incompatibility of health policy decisions with scientific evidence highlights the importance of creating a common language between policy-makers and researchers. It is necessary to set up different types of training sessions that empower the researchers for understanding the needs of health policy-makers to appropriate evidence. International organizations' support could facilitate conducting useful training programmes. Developing evidence based and practical interventions to improve individual and institutional capacity for EIPM such as conducting training programmes or courses for researchers, using mechanisms and networks for effective interaction and cooperation among knowledge producers and knowledge users or relying on incentives that encourage individuals and organizations to be more involved in conducting evidence based research and translating research knowledge into policy can be constructive in this regard.

Generally, to facilitate better use of evidence by policymakers, EIPM needs be strengthened in a systematic way through initiatives aimed at both policy-makers and researchers and the health system as a whole.

\section{Abbreviations}

EIPM: Evidence-informed policy-making.

\section{Supplementary Information}

The online version contains supplementary material available at https://doi. org/10.1186/s12961-022-00816-3.

Additional file 1: Appendix 1a. Search strategy in PubMed. Appendix 1b. Search strategy in Scopus.

Additional file 2: Appendix 2. Interview guide.

\section{Authors' contributions}

All authors contributed to the conception and design of the study; LD and HM contributed to acquisition of data; LD, HM and RM contributed to analysis and interpretation of data; all authors contributed to drafting of the manuscript, and RM revised the manuscript critically. All authors read and approved the final manuscript.

\section{Funding}

No funding is received.

\section{Availability of data and materials}

The datasets used and/or analysed during the current study are available from the corresponding author on reasonable request.

\section{Declarations}

Ethics approval and consent to participate

The ethics committee of the National Institute for Medical Research Development (IR.NIMAD.REC.1397.476) and Tehran University of Medical Sciences (IR. TUMS.VCR.REC.96.02.159.35954) approved the study.

\section{Consent for publication}

Not applicable.

\section{Competing interests}

The author declare no competing interests.

\section{Author details}

${ }^{1}$ Department of Health Policy \& Management, Tabriz Health Services Management Research Center, School of Management and Medical Informatics, Tabriz University of Medical Sciences, Tabriz, Iran. ${ }^{2}$ Social Determinants of Health Services Research Center, Tabriz University of Medical Sciences, Tabriz, Iran. ${ }^{3}$ Health Equity Research Center, Tehran University of Medical Sciences, Tehran, Iran. ${ }^{4}$ Social Determinants of Health Research Center, Lorestan University of Medical Sciences, Khorramabad, Iran. ${ }^{5}$ Knowledge Utilization Research Centre, Tehran University of Medical Sciences, Tehran, Iran. ${ }^{6}$ Knowledge Utilization Research Center, University Research \& Development Center, Tehran University of Medical Sciences, Tehran, Iran. ${ }^{7}$ Research Center for Evidence-Based Health Management, Maragheh University of Medical Sciences, Maragheh, Iran.

${ }^{8}$ National Institute for Health Research, Tehran University of Medical Sciences, Tehran, Iran. ${ }^{9}$ Community Based Participatory Research Center, Tehran University of Medical Sciences, Tehran, Iran.

Received: 4 May 2021 Accepted: 13 January 2022

Published online: 12 February 2022

References

1. Dunn WN. Public policy analysis. London: Routledge; 2015.

2. Howlett M. Policy analytical capacity and evidence-based policy-making: lessons from Canada. Can Public Adm. 2009:52(2):153-75.

3. Buse K, Mays N, Walt G. Making health policy. Maidenhead: McGraw-Hill Education; 2012.

4. Rycroft-Malone J, Seers K, Titchen A, Harvey G, Kitson A, McCormack B. What counts as evidence in evidence-based practice? J Adv Nurs. 2004:47(1):81-90.

5. Champagne F, Lemieux-Charles L. Using knowledge and evidence in health care: multidisciplinary perspectives. Toronto: University of Toronto Press; 2004

6. Sajadi HS, Majdzadeh R, Yazdizadeh B, Mohtasham F, Mohseni M, Doshmangir $L$, Lavis J. A roadmap for strengthening evidence-informed health policy-making in Iran: protocol for a research programme. Health Res Policy Syst. 2019;17(1):1-8.

7. Campbell DM, Redman S, Jorm L, Cooke M, Zwi AB, Rychetnik L. Increasing the use of evidence in health policy: practice and views of policy makers and researchers. Aust N Z Health Policy. 2009;6(1):21.

8. Dobrow MJ, Goel V, Upshur R. Evidence-based health policy: context and utilisation. Soc Sci Med. 2004;58(1):207-17.

9. Hanney SR, Gonzalez-Block MA, Buxton MJ, Kogan M. The utilisation of health research in policy-making: concepts, examples and methods of assessment. Health Res Policy Syst. 2003;1(1):2.

10. Majdzadeh R, Sajadi HS, Yazdizadeh B, et al. Policy options for strengthening evidence-informed health policy-making in Iran: overall SASHA project findings. Health Res Policy Sys. 2022;20:10. https://doi.org/10. 1186/s12961-021-00803-0.

11. Bell E, Waddingham S, Hosken E, Rudling N, Murray S, Martin S, Wagner M. Best practice in using evidence for health policy. In: Bell E, Westert GP, Merrick J, editors. Translational research for primary healthcare. USA: Nova Science Publishers; 2012. p. 89-102. ISBN 978-162417409-4 [Research Book Chapter].

12. Mijumbi-Deve R, Sewankambo NK. A process evaluation to assess contextual factors associated with the uptake of a rapid response service to support health systems' decision-making in Uganda. Int J Health Policy Manag. 2017;6(10):561-71.

13. VanLandingham G, Silloway T. Bridging the gap between evidence and policy makers: a case study of the Pew-MacArthur results first initiative. Public Adm Rev. 2016;76(4):542-6.

14. Uneke CJ, Sombie I, Keita N, Lokossou V, Johnson E, Ongolo-Zogo P. An assessment of policymakers' engagement initiatives to promote evidence informed health policy making in Nigeria. Pan Afr Med J. 2017;27:57.

15. Cairney P, Oliver K. Evidence-based policymaking is not like evidencebased medicine, so how far should you go to bridge the divide between evidence and policy? Health Res Policy Syst. 2017;15(1):35. 
16. Hawkes S, Aulakh BK, Jadeja N, Jimenez M, Buse K, Anwar I, Barge S, Odubanjo MO, Shukla A, Ghaffar A, et al. Strengthening capacity to apply health research evidence in policy making: experience from four countries. Health Policy Plan. 2016;31(2):161-70

17. Bosch-Capblanch X, Lavis JN, Lewin S, Atun R, Røttingen J-A, Dröschel D, Beck L, Abalos E, El-Jardali F, Gilson L. Guidance for evidence-informed policies about health systems: rationale for and challenges of guidance development. PLoS Med. 2012;9(3):e1001185.

18. Tudisca V, Valente A, Castellani T, Stahl T, Sandu P, Dulf D, Spitters H, Van de Goor I, Radl-Karimi C, Syed MA, et al. Development of measurable indicators to enhance public health evidence-informed policy-making. Health Res Policy Syst. 2018;16(1):47.

19. Dakhesh S, Ostovar A, Hamidi A. From transfer of research question to promoting the use of evidence in the process of knowledge translation: self-assessment of researchers in Bushehr University of Medical Sciences. ISMJ. 2018;21(2):134-46.

20. Uneke CJ, Ezeoha A, Ndukwe C, Oyibo P, Onwe F, Bhupinder A. Enhancing policy makers' capacity for evidence-informed policy making through mentorship: a reflection on the Nigeria experience. Evid Policy. 2014;10(1):137-59.

21. Haines A, Kuruvilla S, Borchert M. Bridging the implementation gap between knowledge and action for health. Bull World Health Organ. 2004;82:724-31.

22. Sajadi HS, Majdzadeh R, Ehsani-Chimeh E, Yazdizadeh B, Nikooee S, Pourabbasi A, Lavis J. Policy options to increase motivation for improving evidence-informed health policy-making in Iran. Health Res Policy Syst. 2021;19(1):91.

23. Majdzadeh R, Yazdizadeh B, Nedjat S, Gholami J, Ahghari S. Strengthening evidence-based decision-making: is it possible without improving health system stewardship? Health Policy Plan. 2012;27(6):499-504.

24. Doshmangir L, Moshiri E, Mostafavi H, Sakha MA, Assan A. Policy analysis of the Iranian Health Transformation Plan in primary healthcare. BMC Health Serv Res. 2019;19(1):670.

25. Doshmangir L, Najafi B, Mostafavi H, Moshiri E. Future development through the past: pathology of the financing dimension of Iran's Health Transformation Plan. ClinicoEcon Outcomes Res. 2020;12:345-54.

26. Behzadifar M, Azari S, Gorji HA, Martini M, Bragazzi NL. The hepatitis C virus in Iran: health policy, historical, ethical issues and future challenges. J Prev Med Hyg. 2020;61(1):E109-e118.

27. Moher D, Liberati A, Tetzlaff J, Altman DG. Preferred reporting items for systematic reviews and meta-analyses: the PRISMA statement. Int J Surg 2010;8(5):336-341

28. Lavis J, Davies H, Oxman A, Denis J-L, Golden-Biddle K, Ferlie E. Towards systematic reviews that inform health care management and policymaking. J Health Serv Res Policy. 2005;10(1_suppl):35-48.

29. Uneke CJ, Ezeoha AE, Ndukwe CD, Oyibo PG, Onwe F. Promotion of evidence-informed health policymaking in Nigeria: bridging the gap between researchers and policymakers. Glob Public Health. 2012;7(7):750-65

30. Dreisinger M, Leet TL, Baker EA, Gillespie KN, Haas B, Brownson RC. Improving the public health workforce: evaluation of a training course to enhance evidencebased decision making. J Public Health Manag Pract: JPHMP. 2008;14(2):138-43.

31. Uneke CJ, Ezeoha AE, Uro-Chukwu H, Ezeonu CT, Ogbu O, Onwe F, Edoga C. Improving Nigerian health policymakers' capacity to access and utilize policy relevant evidence: outcome of information and communication technology training workshop. Pan Afr Med J. 2015. https://doi.org/10.11604/pamj.2015.21.212.6375.

32. Ju H, Hewson K. Health technology assessment and evidence-based policy making: Queensland Department of Health experience. Int J Technol Assess Health Care. 2014;30(6):595-600.

33. Khan S, Moore JE, Gomes T, Camacho X, Tran J, McAuley G, Juurlink DN, Paterson M, Laupacis A, Mamdani MM. The ontario drug policy research network: bridging the gap between research and drug policy. Health policy (Amsterdam, Netherlands). 2014;117(3):392-8

34. Langlois EV, Montekio VB, Young T, Song K, Alcalde-Rabanal J, Tran $\mathrm{N}$. Enhancing evidence informed policymaking in complex health systems: lessons from multi-site collaborative approaches. Health Res Policy Syst. 2016;14(1):1-11

35. Lavis JN, Røttingen J-A, Bosch-Capblanch X, Atun R, El-Jardali F, Gilson L, Lewin S, Oliver S, Ongolo-Zogo P, Haines A. Guidance for evidence-informed policies about health systems: linking guidance development to policy development. PLoS Med. 2012;9(3):e1001186.

36. Lefebre N. Knowledge to action: integrating the use of evidence in management decision making. In: Healthcare management forum, 2010. Elsevier; 2010, p. 48-52.

37. Mavoa H, Waqa G, Moodie M, Kremer P, McCabe M, Snowdon W, Swinburn B. Knowledge exchange in the Pacific: the TROPIC (Translational Research into Obesity prevention Policies for Communities) project. BMC Public Health. 2012;12(1):1-9.

38. Makkar SR, Howe M, Williamson A, Gilham F. Impact of tailored blogs and content on usage of Web CIPHER - an online platform to help policymakers better engage with evidence from research. Health Res Policy Syst. 2016;14(1):1-13.

39. Ouimet M, Lapointe L, Léon G. Examining the feasibility and impact of a graduate public administration course in evidence-informed policy. Evid Policy: A J Rese Debate Pract. 2015;11(2):149-68.

40. Uneke CJ, Sombie I, Keita N, Lokossou V, Johnson E, Ongolo-Zogo P, Uro-Chukwu HC. Promoting evidence informed policy making in Nigeria: a review of the maternal, newborn and child health policy development process. Health Promot Perspect. 2017;7(4):181.

41. White R, Charalambous S, Cardenas V, Hippner P, Sumner T, Bozzani F, Mudzengi D, Houben R, Collier D, Kimerling M. Evidence-informed policy making at country level: lessons learned from the South African Tuberculosis Think Tank. Int J Tuberc Lung Dis. 2018;22(6):606-13.

42. Waqa G, Mavoa H, Snowdon W, Moodie M, Schultz J, McCabe M, Kremer P, Swinburn B. Knowledge brokering between researchers and policymakers in Fiji to develop policies to reduce obesity: a process evaluation. Implementation Sci. 2013;8(1):1-11.

43. Waters E, Armstrong R, Swinburn B, Moore L, Dobbins M, Anderson L, Petticrew M, Clark R, Conning R, Moodie M, et al. An exploratory cluster randomised controlled trial of knowledge translation strategies to support evidence-informed decision-making in local governments (The KT4LG study). BMC Public Health. 2011;11(1):1-8.

44. Uneke CJ, et al. An assessment of national maternal and child health policy-makers' knowledge and capacity for evidence-informed policymaking in Nigeria. Int J Health Policy Manag. 2017;6(6):309-16https:// doi.org/10.15171/ijhpm.2016.132.

45. Innvaer S, Vist G, Trommald M, Oxman A. Health policymakers' perceptions of their use of evidence: a systematic review. J Health Serv Res Policy. 2002;7(4):239-44.

46. Makkar SR, Brennan S, Turner T, Williamson A, Redman S, Green S. The development of SAGE: a tool to evaluate how policymakers' engage with and use research in health policymaking. Res Eval. 2016;25(3):315-28.

47. Uneke CJ, Aulakh BK, Ezeoha AE, Ndukwe CD, Onwe F. Bridging the divide between research and policy in Nigeria: the role of a health policy advisory committee. J Public Health Policy. 2012;33(4):423-9.

48. Langlois EV, Becerril Montekio V, Young T, Song K, Alcalde-Rabanal J, Tran N. Enhancing evidence informed policymaking in complex health systems: lessons from multi-site collaborative approaches. Health Res Policy Syst. 2016;14:20.

49. Makkar SR, Turner T, Williamson A, Louviere J, Redman S, Haynes A, Green S, Brennan S. The development of ORACLe: a measure of an organisation's capacity to engage in evidence-informed health policy. Health Res Policy Syst. 2016;14:4.

50. Aldrich MC, Hidalgo B, Widome R, Briss P, Brownson RC, Teutsch SM The role of epidemiology in evidence-based policy making: a case study of tobacco use in youth. Ann Epidemiol. 2015;25(5):360-5.

51. Grollmann P, Hoppe M. Methods and instruments for the evaluation and monitoring of vocational education and training systems: a basis for evidence-based policy making? Res Comp Int Educ. 2011;6(3):250-4.

52. Shroff ZC, Javadi D, Gilson L, Kang R, Ghaffar A. Institutional capacity to generate and use evidence in LMICs: current state and opportunities for HPSR. Health Res Policy Syst. 2017;15(1):94.

53. Uneke CJ, Ezeoha AE, Uro-Chukwu HC, Ezeonu CT, Igboji J. Promoting researchers and policy-makers collaboration in evidence-informed policy-making in Nigeria: outcome of a two-way secondment model between university and health ministry. Int J Health Policy Manag. 2018;7(6):522-31. 
54. Andermann A, Pang T, Newton JN, Davis A, Panisset U. Evidence for health I: producing evidence for improving health and reducing inequities. Health Res Policy Syst. 2016;14:18.

55. Brennan SE, McKenzie JE, Turner T, Redman S, Makkar S, Williamson A, Haynes A, Green SE. Development and validation of SEER (Seeking, Engaging with and Evaluating Research): a measure of policymakers' capacity to engage with and use research. Health Res Policy Syst. 2017;15(1):1.

56. El-Jardali F, Lavis J, Moat K, Pantoja T, Ataya N. Capturing lessons learned from evidence-to-policy initiatives through structured reflection. Health Res Policy Syst. 2014;12:2.

57. Shahmoradi L, Safadari R, Jimma W. Knowledge management implementation and the tools utilized in healthcare for evidencebased decision making: a systematic review. Ethiop J Health Sci. 2017;27(5):541-58.

58. Mijumbi RM, Oxman AD, Panisset U, Sewankambo NK. Feasibility of a rapid response mechanism to meet policymakers' urgent needs for research evidence about health systems in a low income country: a case study. Implement Sci. 2014;9:114.

59. Juzwishin DW. Evidence informed decision-making in healthcare: the case for health technology assessment. World Hosp Health Serv. 2010;46(1):10-2.

60. Uzochukwu B, Onwujekwe O, Mbachu C, Okwuosa C, Etiaba E, Nystrom $M E$, Gilson $L$. The challenge of bridging the gap between researchers and policy makers: experiences of a Health Policy Research Group in engaging policy makers to support evidence informed policy making in Nigeria. Glob Health. 2016;12(1):67.

61. Ouimet M, Lavis JN, Leon G, Ellen ME, Bedard PO, Grimshaw JM, Gagnon MP. A cross-sectional survey of supports for evidence-informed decisionmaking in healthcare organisations: a research protocol. Implement Sci. 2014;9:146.

62. Makkar SR, Williamson A, Turner T, Redman S, Louviere J. Using conjoint analysis to develop a system of scoring policymakers' use of research in policy and program development. Health Res Policy Syst. 2015;13:35.

63. Field $\mathrm{P}$, Gauld $\mathrm{R}$, Lawrence $M$. Enhancing evidence use in public health nutrition policymaking: theoretical insights from a New Zealand case study. Health Res Policy Syst. 2016;14(1):84.

64. Majdzadeh R, Sadighi J, Nejat S, Mahani AS, Gholami J. Knowledge translation for research utilization: design of a knowledge translation model at Tehran University of Medical Sciences. J Contin Educ Health Prof. 2008;28(4):270-7.

65. Kawabuchi K. Evidence-based policy making for sustainable healthcare in Japan: 2025 and beyond. Jpn Hosp. 2013;32:29-37.

66. Lavis JN, Panisset U. EVIPNet Africa's first series of policy briefs to support evidence-informed policymaking. Int J Technol Assess Health Care. 2010;26(2):229-32.

67. Doshmangir L, Yazdizadeh B, Sajadi HS, Mohtasham F, Majdzadeh R. What is going on in the future for evidence-informed health policymaking in Iran? J Evid Based Med. 2021;14(4):285-90. https://doi.org/10.1111/jebm. 12458.

68. Perrier L, Mrklas K, Lavis JN, Straus SE. Interventions encouraging the use of systematic reviews by health policymakers and managers: a systematic review. Implement Sci. 2011;6(1):43.

69. Caiaffa WT, Friche AA, Dias MA, Meireles AL, Ignacio CF, Prasad A, Kano M. Developing a conceptual framework of urban health observatories toward integrating research and evidence into urban policy for health and health equity. J Urban Health. 2014;91(1):1-16.

70. Best A, Terpstra JL, Moor G, Riley B, Norman CD, Glasgow RE. Building knowledge integration systems for evidence-informed decisions. J Health Organ Manag. 2009;23(6):627-41.

71. Tonmukayakul U, Velasco RP, Tantivess S, Teerawattananon Y. Lessons drawn from research utilization in the maternal iodine supplementation policy development in Thailand. BMC Public Health. 2012;12:391.

\section{Publisher's Note}

Springer Nature remains neutral with regard to jurisdictional claims in published maps and institutional affiliations.

Ready to submit your research? Choose BMC and benefit from:

- fast, convenient online submission

- thorough peer review by experienced researchers in your field

- rapid publication on acceptance

- support for research data, including large and complex data types

- gold Open Access which fosters wider collaboration and increased citations

- maximum visibility for your research: over 100M website views per year

At BMC, research is always in progress.

Learn more biomedcentral.com/submissions 